\title{
Decadal variation of ocean heat content and tropical cyclone activity over the Bay of Bengal
}

\author{
SANKAR NATH ${ }^{1, *}$, S D Kotal ${ }^{1}$ and P K Kundu ${ }^{2}$ \\ ${ }^{1}$ India Meteorological Department, Mausam Bhavan, Lodi Road, New Delhi 110 003, India. \\ ${ }^{2}$ Department of Mathematics, Jadavpur University, Kolkata 700 032, India. \\ *Corresponding author.e-mail: saulnov07@gmail.com
}

The upper ocean heat content up to $700 \mathrm{~m}$ depth $\left(\mathrm{OHC}_{700}\right)$ is an important climatic parameter required for atmospheric and oceanographic studies like a cyclone. In this study, therefore, an attempt has been made to examine the inter-decadal variations of tropical cyclone (TC) activity and $\mathrm{OHC}_{700}$ over the Bay of Bengal (BOB) for the post-monsoon season (October-December) during 1955-2013 periods. The sea-surface temperature (SST), geopotential height at $500 \mathrm{hPa}$, low-level vorticity at $850 \mathrm{hPa}$, vertical wind shear between 200 and $850 \mathrm{hPa}$, middle tropospheric humidity at $500 \mathrm{hPa}$ and outgoing long-wave radiation are also being studied using seasonal mean data. The results show a significant inter-decadal variation during 1955-2013, with two distinct decadal periods: active decadal period (ADP) (1955-1988) and inactive decadal period (IDP) (1989-2013). The anomalies of these parameters are opposite in phase for two periods. It is found that the large scale atmospheric features and oceanic parameters have significant inter-decadal variability, but frequency of the tropical cyclone is attributed to the variation in the atmospheric dynamic and thermodynamic conditions rather than the variation of oceanic parameters $\mathrm{OHC}_{700}$ and SSTs during the post-monsoon season.

\section{Introduction}

The natural hazards caused by the tropical cyclone (TCs) in the cyclone-prone area have high economic and humanitarian implications. Emanuel (1999) mentioned that the upper ocean heat content is one of the key factors for the genesis and intensification of the cyclone. Over the decades, the oceans have been considered as one of the major contributors to climate change due to their large thermal inertia. They store huge amounts of solar heat energy within the upper few layers on shorter time scales and in the deeper layers on longer time periods. The heat flux exchange between the atmosphere and the ocean takes place from the upper layers (Momin et al. 2011). It also observed that a large part of the change in ocean heat content during the past 50 years has occurred in the upper $700 \mathrm{~m}$ of the world ocean (Levitus et al. 2005). Therefore, monitoring of the upper ocean thermal structure is important in the study of cyclone-ocean interactions including variation of the cyclone. Thus, the ocean heat content up to a depth of $700 \mathrm{~m}\left(\mathrm{OHC}_{700}\right)$ is considered for the study of decadal variations of cyclone activity.

Numerous previous studies demonstrated that the tropical cyclone activity depends on both thermodynamics and dynamical factors, which include sea surface temperature (SST), vertical wind shear, thermodynamic instability, low-level relative vorticity, mid-tropospheric moisture, etc. (Palmen 1948; Gray 1968). Among these factors, high SST is favourable for tropical cyclone formation and

Keywords. Tropical cyclone; decadal; Bay and Bengal; ocean heat content. 


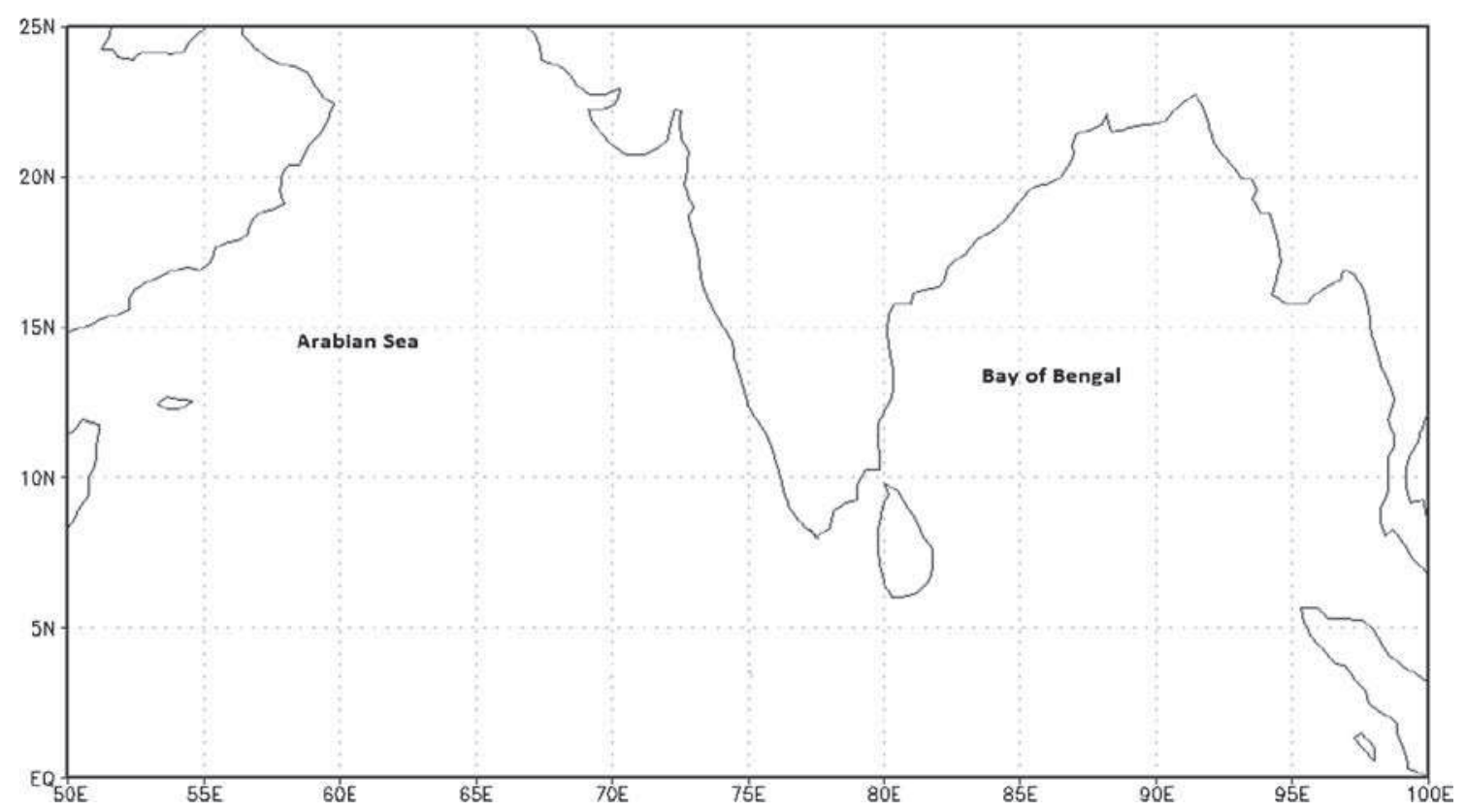

Figure 1. Schematic of the study area: The Bay of Bengal.

intensification, while strong vertical wind shear is unfavourable for the formation of cyclones. Early studies revealed a significant relationship between the tropical cyclone genesis and intensity changes with the tropical cyclone heat potential (TCHP) which is a parameter describing OHC (Ali et al. 2007; Wada and Usui 2007; Wada and Chan 2008; Goni et al. 2009; Shay and Brewster 2010).

The modulations of seasonal TC activity by large scale environmental conditions have also been reported by several researchers (Gray 1977; Chu et al. 2007). Other studies have shown a long-term variability of tropical cyclone frequency in different ocean basins (Neumann 1993; Wang and Chan 2002).

Shyamala and Iyer (1996) found that there is statistically significant decadal variability with decreasing tendency in decadal frequency of cyclonic storms in the Arabian Sea. Singh and Route (1999) found that the variation in the frequency of cyclonic disturbances, to some extent, associated with ENSO and excess monsoon years. Srivastava et al. (2000) found that there are significant trends in the frequency of storms over both the Arabian Sea and Bay of Bengal. Jayanthi (1997) found large decadal variability in the frequency of BOB basin cyclones without any long-term trend. Joseph and Xavier (1999) also found a 40-year periodicity in the frequency of TCs in the BOB basin. The role of UOHC in enhancing convection and providing heat supply for more number of low pressure systems formed over the BOB during 2010 compared to 2009 monsoon season also discussed by previous study (Gera et al. 2013).

There have been extensive studies on the tropical cyclone genesis (Kotal et al. 2009; Nath et al. 2013) and intensity prediction (Kotal et al. 2008) over BOB. The studies on the long-term variability of tropical cyclone frequency, in comparison, has received relatively less attention, particularly, for post-monsoon season although several studies have documented the variation of TC activity with sea surface temperature and atmospheric circulation for monsoon periods. However, the ocean heat content up to a depth of $700 \mathrm{~m}\left(\mathrm{OHC}_{700}\right)$ on interdecadal variability of $\mathrm{TC}$ activity, which may be equally important have not been examined. This has motivated the present study. In this study, we investigate the interdecadal changes in post monsoon cyclone frequency over the BOB, based on analyses of SST, $\mathrm{OHC}_{700}$, geopotential height at $500 \mathrm{hPa}$, relative vorticity at $850-\mathrm{hPa}$, vertical wind shear of zonal wind, outgoing longwave radiation, relative humidity at $500-\mathrm{hPa}$ and cyclone data. Relevant links of inter-decadal changes to anomalies of $\mathrm{OHC}_{700}$, SST and large scale circulation with TCs frequency are discussed.

\subsection{Study area}

In the present study, the Bay of Bengal region (BOB: $5^{\circ}-22.5^{\circ} \mathrm{N} ; 80^{\circ}-100^{\circ} \mathrm{E}$ ) has been considered as the study area (figure 1). The Indian Ocean is least understood and limited studies are 
available because of its complex nature (Swallow 1984). The wide varieties of oceanographic and atmospheric phenomena are the result of semiannually reversing monsoon. As a result, India experiences four primary seasons, namely, winter, pre-monsoon, southwest monsoon and postmonsoon season. The pre-monsoon (March-May) and post-monsoon (October-December) are the two cyclone seasons. The large population density and low socio-economic condition in the coastal belt of NIO leads to devastating disasters by the landfall of cyclone (Belanger et al. 2012). A little increase in the frequency and intensity of tropical cyclones may lead to more damage. Therefore, it is desirable that the trend and the variation in the tropical cyclone be examined in addition to intensity.

The structure of this paper is as follows. Data and methodology are described in section 2 and result and discussion are presented in section 3 . Concluding remarks are given in section 4 .

\section{Data and methodology}

The seasonal tropical cyclone series of the Bay of Bengal from 1955 to 2013 was obtained from the frequency of cyclone disturbance archives of the India Meteorological Department (IMD), New Delhi, RSMC website (www.rsmcnewdelhi.imd. gov.in) which is one of the World Meteorological Organization (WMO) recognized Regional Specialized Meteorological Centre (RSMC) for tropical cyclone warning advisories.

Seasonal outgoing long-wave radiation, zonal wind data at the 850 and $200 \mathrm{hPa}$ levels, geopotential height at $500 \mathrm{hPa}$ and relative humidity at $500 \mathrm{hPa}$ over the region under analysis are derived from the National Centers for Environmental Prediction-National Center for Atmospheric Research (NCEP-NCAR). The NCEP-NCAR reanalysis data have a horizontal resolution of $2.5^{\circ} \times 2.5^{\circ}$ latitude-longitude and are available from 1948 to the present. The SST data from the NCEPNCAR reanalysis are used to investigate interdecadal changes in SST over the tropics. Ocean heat content $\left(\mathrm{OHC}_{700}\right)$ up to the depth of $700 \mathrm{~m}$ data are derived from NOAA/NESDIS/NOAD data and used for the study. The vertical wind shear is calculated as the difference of zonal wind $(\mathrm{u})$ between 850 and $200 \mathrm{hPa}$ averaged over $80^{\circ}-$ $100^{\circ} \mathrm{E}$. Time series of relative vorticity at $850 \mathrm{hPa}$ is also calculated for BOB during post-monsoon season.

All the above parameters have been averaged over $\mathrm{BOB}$ region extending from $80^{\circ}-100^{\circ} \mathrm{E}, 5^{\circ}-$ $22.5^{\circ} \mathrm{N}$. A statistical analysis is applied here to objectively identify the timing of change point years in the TC series over the BOB. The details of the change point analysis are well described in Elsner et al. (2000) and Chu (2002). Using this analysis, 59-year period of study is divided into two decades, viz., ADP from 1955-1988 and IDP from 1989-2013 as the frequency of tropical cyclone anomalies change significantly around 1989. Anomalies of various parameters are calculated based on the period 1955-2013. 11-year running mean of the frequency of cyclone anomaly is also studied as the variation of $\mathrm{TC}$ is more discernible, once time series are smoothened for small-period oscillations.

The frequency of tropical cyclone, $\mathrm{OHC}_{700}$, sea surface temperature anomaly (SSTA) and atmospheric parameter anomalies are standardized and 11-year running mean is plotted to study decadal variability. The anomaly is simply a deviation from the long-term mean for 1955-2013. Large scale environmental conditions instrumental for TC incidences during the post-monsoon season between two periods are also investigated.

\section{Results and discussion}

\subsection{Climatology}

The average annual frequency of tropical cyclones is about 5 (about $5-6 \%$ of the global annual average), whereas the globe's average is about 80 . The frequency is more in the Bay of Bengal than in the Arabian Sea, the ratio being is $4: 1$. The monthly frequency showed a bi-model character, with a primary peak in November and a secondary peak in May. May-June and October-November are the months of severe cyclones. During the monsoon months (July-September), the intensity of tropical cyclones is less.

The climatological distribution of the total annual and the post-monsoon season frequency of the TC from 1955 to 2013 formed over the Bay of Bengal are presented in figure 2. The average number of annual and post-monsoon season cyclones formed is 3.6 and 2.2 , respectively. A large variation in annual and post-monsoon season cyclone formation is observed. The standard deviation of annual and post-monsoon season is 1.6 ( $44 \%$ of mean value) and 1.3 (54\% of mean value), respectively. The correlation coefficient between the number of post-monsoon and annual cyclones is 0.80 , which is significant at $99.9 \%$ confidence level. The frequency of tropical cyclones formed over, the Bay of Bengal both in annual and postmonsoon season for the period 1955-2013 shows a significant decreasing trend of $99.9 \%$ and $95 \%$, respectively. 


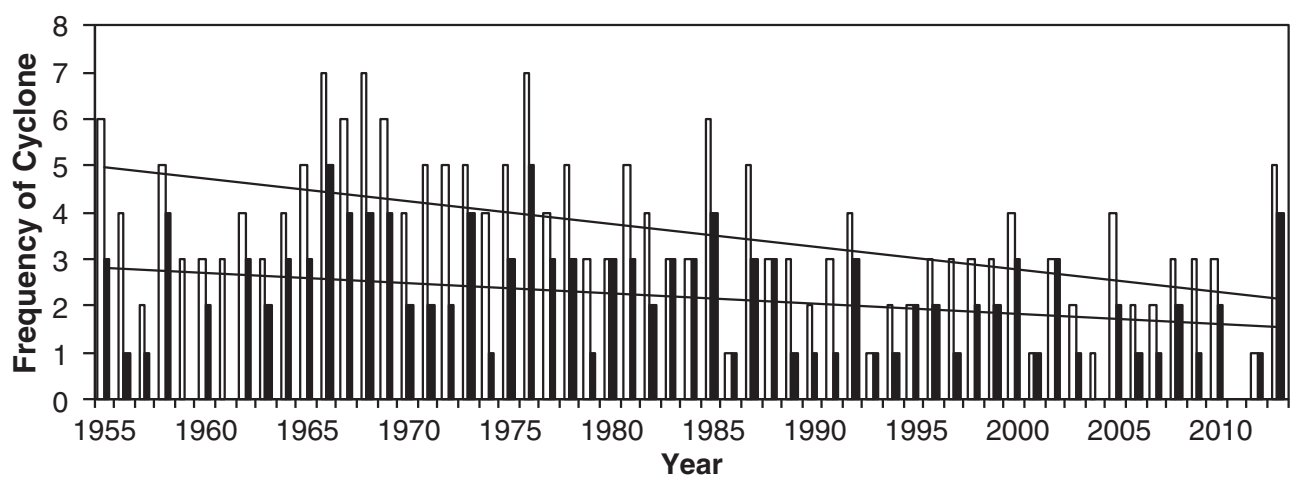

Figure 2. The climatological distribution of the total annual and the post-monsoon season frequency of the TC from 1955 to 2013 formed over the Bay of Bengal. The unshaded bar is for annual tropical cyclone frequency and the shaded bar is for seasonal tropical cyclone frequency.

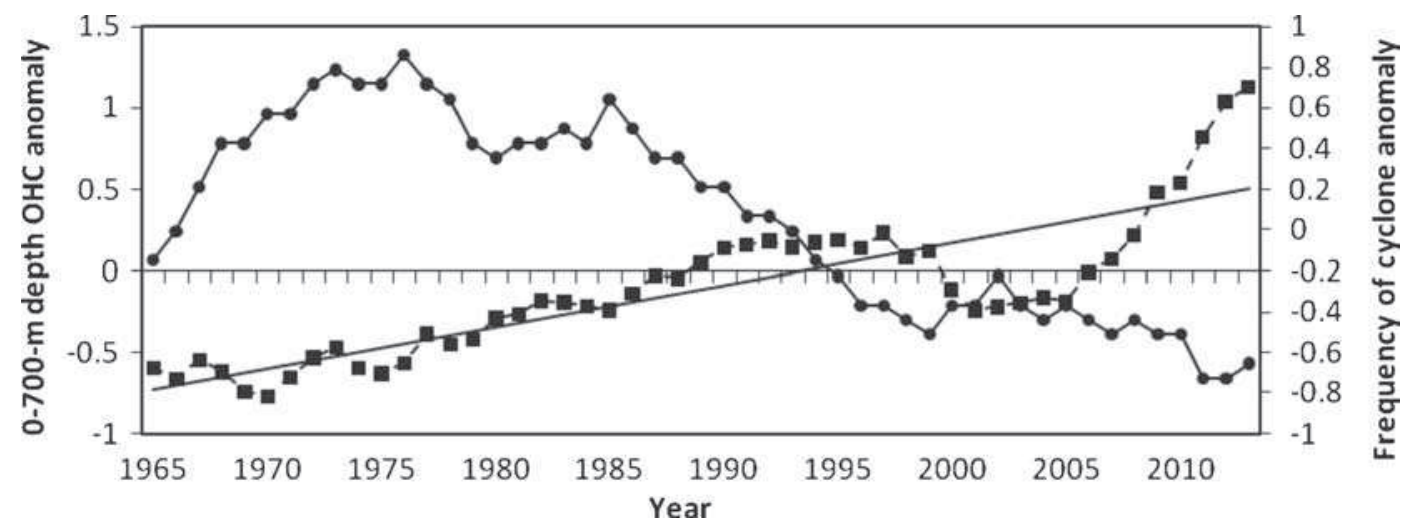

Figure 3. 11-year running mean of standardized anomalies of ocean heat content $\left(\mathrm{OHC}_{700}\right)$ from the surface to $700-\mathrm{m}$ depth over the Bay of Bengal during the post-monsoon season. Solid line with a solid circle represents the TC frequency value. Solid line with open square represents the $\mathrm{OHC}_{700}$.

\subsection{Inter-decadal changes}

Palmen (1948) showed that hurricanes form over regions where sea surface temperature (SST) is greater than $26^{\circ} \mathrm{C}$. In addition to high SST, other important environmental factors for genesis of tropical cyclones are: large Coriolis force, high low level relative vorticity, weak vertical wind shear and moisture in the middle troposphere (Gray 1975). Some more recent studies (Rajeevan et al. 2000; Mandke and Bhide 2003) have shown that since mid-1980s, the storm frequency has shown declining trends on a decadal scale, in spite of increasing SSTs during the monsoon season. In addition to these studies, a number of studies have explored that the cyclones are also greatly influenced by the underlying ocean surface over which they form and travel, and the energy is unlimited as long as cyclone remains over warm water (Leipper and Volgenau 1972; Shay et al. 2000). During the past 50 years, large part of the change in ocean heat content has occurred in the upper 700-m of the world ocean (Levitus et al. 2005).
Therefore, the inter-decadal changes of tropical cyclone frequency in post-monsoon season associated with changes in the $\mathrm{OHC}_{700}$, SSTs and the large scale environmental conditions is investigated.

Since, the dynamical and thermodynamical environments of both the ocean and atmosphere change with respect to long-term variations on global scale, tropical cyclone activity over the Indian region may also be influenced by such changes.

\subsubsection{Ocean heat content up to depth of $700 \mathrm{~m}$}

Levitus et al. (2005) have confirmed Rossby's (1959) suggestion that the dominant component of the variability of Earth's heat balance is ocean heat content. Revelle et al. (1965) first reported that the warming of the world ocean is due to increasing atmospheric greenhouse gases. Over the past 50 years, the oceans have absorbed about $90 \%$ of the total heat added to the climate system (Bindoff 
et al. 2007), while the rest goes into melting sea and land ice, and warming the land surface and atmosphere. Therefore, monitoring of the upper ocean thermal structure is important in the study of cyclone-ocean interactions including variation of the cyclone. Thus, the OHC up to a depth of 700 $\mathrm{m}\left(\mathrm{OHC}_{700}\right)$ is considered for the study of decadal variations of cyclone activity over the $\mathrm{BOB}$.

The 11-year running mean of standardized anomaly of $\mathrm{OHC}_{700}$ from the surface to $700 \mathrm{~m}$ depth over Bay of Bengal during the post-monsoon season is presented in figure 3. The variability of $\mathrm{OHC}_{700}$ is such that the anomaly is negative around 1965 and then increases till the end of 1980s and a change in their sign is observed thereafter and then maintained almost positive till 2013. This change of sign around 1989 is consistent with the decadal variability of tropical cyclone frequency. The mean values of TC frequency anomaly and $\mathrm{OHC}_{700}$ anomaly for the ADP periods are 0.49 and -0.43 and -0.32 and 0.19 for IDP respectively (table 1). This implied that the TC frequency and $\mathrm{OHC}_{700}$ variations are strong opposite in phase in both the periods. This is also reflected in figure 3 . The years with positive anomaly in the ADP and IDP in TC frequency are $91 \%$ and $19 \%$, whereas

Table 1. 11-year running mean of standardized anomaly of different parameters calculated during the ADP of TCs (1955-1988) and the IDP of TCs (1989-2013).

\begin{tabular}{lcc}
\hline Parameters & $\begin{array}{c}\text { ADP } \\
(1955-1988)\end{array}$ & $\begin{array}{c}\text { IDP } \\
(1989-2013)\end{array}$ \\
\hline Ocean heat content up & -0.43 & 0.19 \\
$\quad$ to depth of $700 \mathrm{~m}$ & & \\
Sea surface temperature & -0.59 & 0.47 \\
Vertical wind shear 850-200 hPa & -0.12 & 0.27 \\
Relative humidity at 500 hPa & 0.39 & -0.40 \\
Vorticty at 850 hPa & 0.08 & 0.02 \\
Geoptential height at $850 \mathrm{hPa}$ & -0.50 & 0.59 \\
Outgoing long-wave radiation & -0.23 & 0.16 \\
\hline
\end{tabular}

with negative anomaly are $9 \%$ and $81 \%$, respectively. However, the years with negative anomaly in $\mathrm{ADP}$ and IDP for $\mathrm{OHC}_{700}$ are $100 \%$ and $31 \%$, whereas with positive anomalies are $0 \%$ and $69 \%$, respectively. It is clear from the figure that there is an increasing trend of $\mathrm{OHC}_{700}$ anomaly, whereas anomaly of frequency of the TC shows a decreasing trend. These trends are tested using Mann-Kendall rank statistic test for significance and found to be significant at $99.9 \%$ significant level. Thus, it is seen that the warm $\mathrm{OHC}_{700}$ alone is not sufficient for the genesis of tropical cyclones.

\subsubsection{Sea surface temperature}

As described in the introduction, the relationship between the SST and tropical cyclone formation has been recognized for many years. Most tropical cyclones form over tropical warm oceans, where a threshold minimum value of SST is of the order of $26^{\circ}-27^{\circ} \mathrm{C}$ (Palmen 1948). Royer et al. (1998) indicate that this value may have to increase in a warmer climate as the deep convection normally initiated at $26^{\circ} \mathrm{C}$ also depends on the temperature of the upper troposphere. Therefore, the SST may be one of the important parameters for the decadal variations of cyclone activity over the study area.

Figure 4 shows the 11-year running mean of standardized anomaly of sea surface temperature (SSTA) for the seasonal average over Bay of Bengal for the period 1955-2013. The figure shows that the SST anomaly is found to be a small negative from 1965 to 1988 and a change in their sign is observed thereafter. It is also remarkable that the anomaly of SST changed sign around 1988 and steadily increased thereafter. The trend line of SST anomaly shows significant increasing trend $(99.9 \%)$, whereas the TC frequency is of decreasing trend (figure 3). Table 1 shows that the SSTA for the ADP and IDP are -0.59 and 0.47 , respectively. The TC frequency and SST anomaly variations are opposite in phase. The result is not

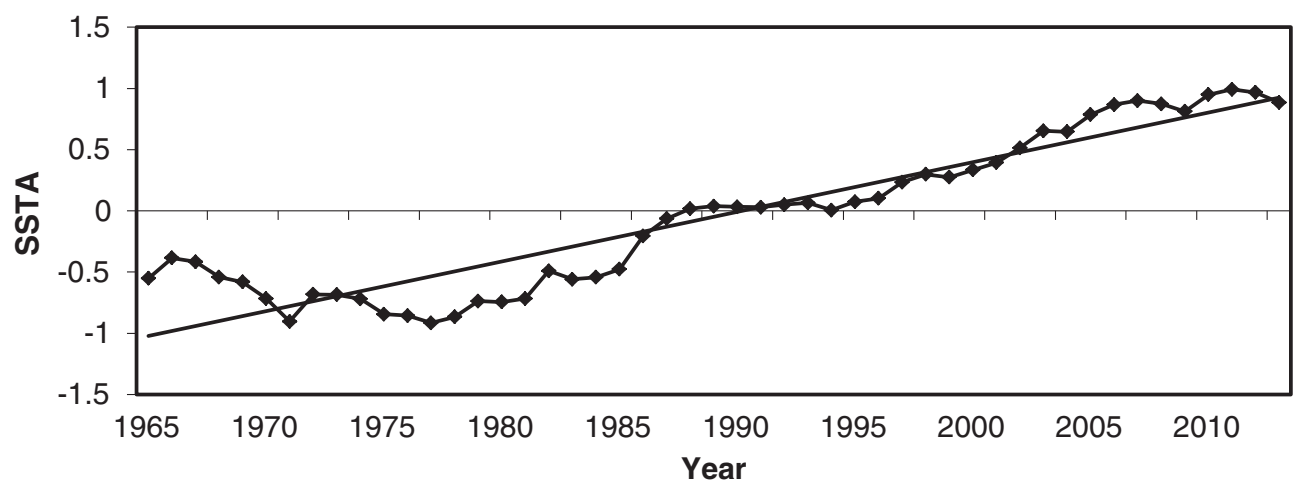

Figure 4. 11-year running mean of standardized anomaly of sea surface temperature for the seasonal average over the Bay of Bengal for the period 1955-2013. 


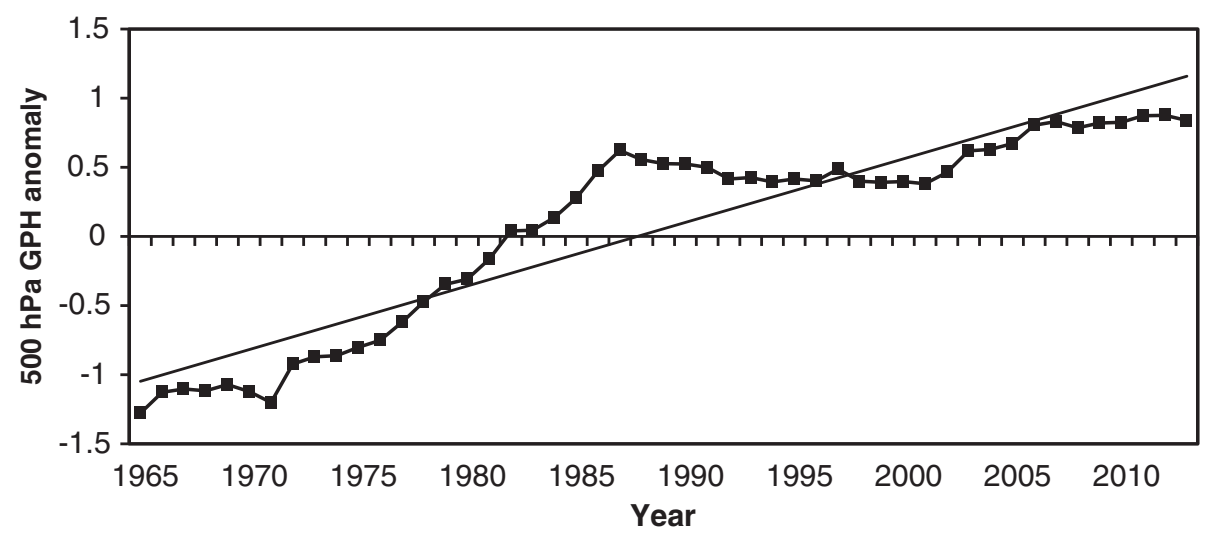

Figure 5. 11-year running mean of standardized anomaly of geopotential height at $500 \mathrm{hPa}$ for the seasonal average over the Bay of Bengal for the period 1955-2013.

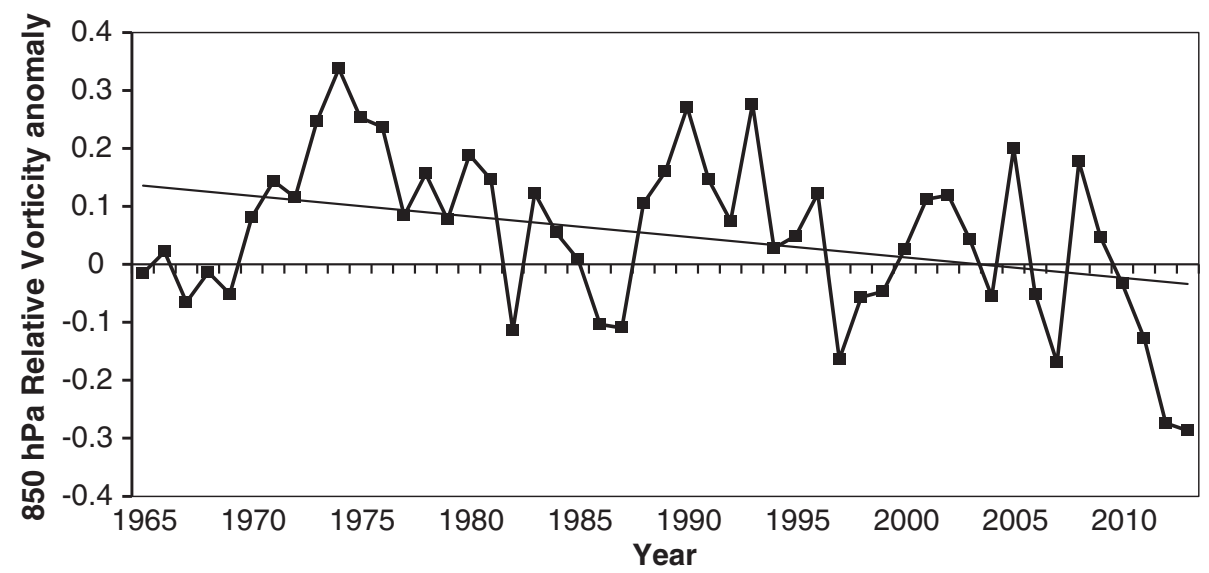

Figure 6. 11-year running mean of standardized anomalies of vorticity at $850 \mathrm{hPa}$ for the seasonal average over Bay of the Bengal for the period 1955-2013.

physically significant, as the number of TC should increase with the increase of SST as the warm SSTs are expected to fuel the overlying atmosphere with additional warmth and moisture, thereby reducing atmospheric stability and increasing the likelihood of deep tropical convection. However, the result is consistent with the previous studies that since the mid-1980s, the tropical cyclone frequency has shown declining trends on a decadal scale, in spite of increasing SSTs during the monsoon season (Rajeevan et al. 2000; Mandke and Bhide 2003).

\subsubsection{Variation in atmospheric parameters} (geopotential height at 500, $850 \mathrm{hPa}$ vorticity, vertical wind shear, middle tropospheric relative humidity, outgoing long wave radiation)

The role of large scale environmental factors (e.g., vertical wind shear, low-level relative vorticity and mid-tropospheric moisture, etc.) in TC formation has been the subject of research since its inception in the late 1960s (Gray 1968). Therefore, the environmental factors such as vertical wind shear, low-level relative vorticity, geopotential height, outgoing long-wave radiation and mid-tropospheric moisture are analyzed to find the relationship with frequency of cyclones.

The geopotential height at $500 \mathrm{hPa}$ may be one of the important parameters for cyclone activity, as low geopotential height indicates the trough or low pressure, which provide more favourable conditions for tropical cyclone genesis and development. From the time series plot (figure 5), it is found that the 11-year running mean of standardized anomalies of geopotential height at $500 \mathrm{hPa}$ shows an increasing trend with $99.9 \%$ significant level, which is just the opposite to that of the decreasing trend of TC frequency during the post-monsoon season. The anomaly is largely negative around 1965 and then increases till early 1980s and it changes sign to positive after that period until 2013. A positive anomaly of geopotential height in recent decade (IDP) is unfavorable for cyclone genesis and also consistent with the decrease of cyclone frequency. 


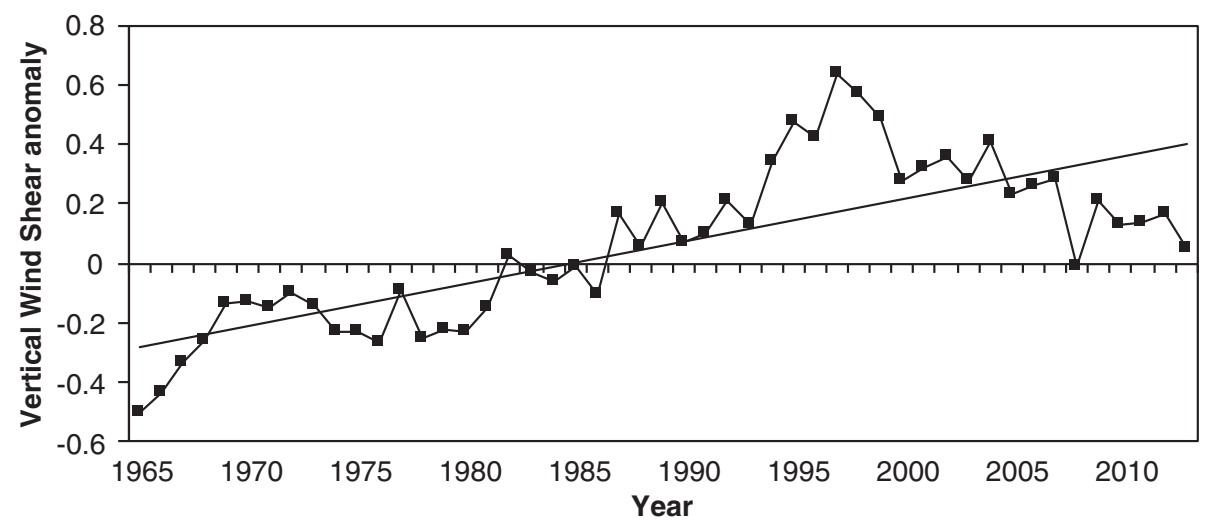

Figure 7. 11-year running mean of standardized anomalies of vertical wind shear between 850 and $200 \mathrm{hPa}$ for the seasonal average over the Bay of Bengal for the period 1955-2013.

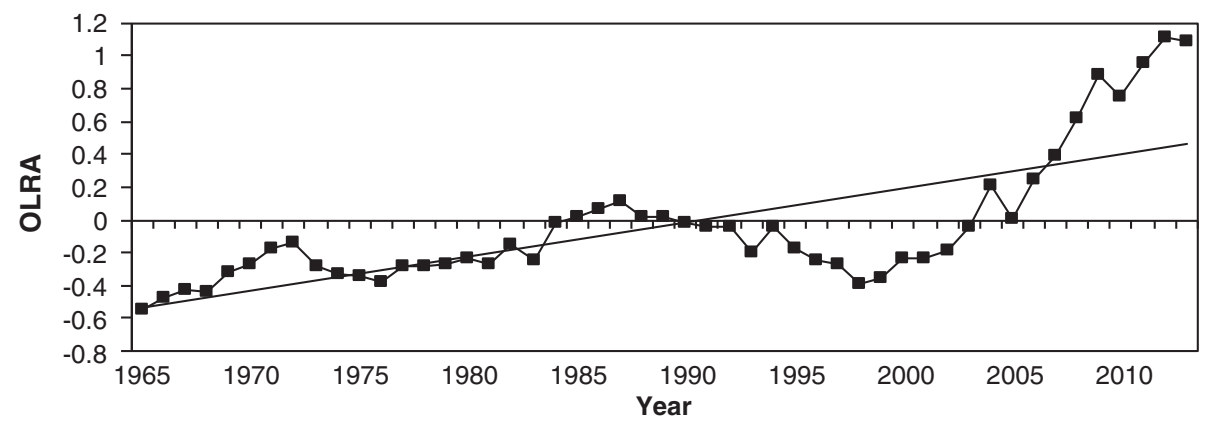

Figure 8. 11-year running mean of standardized anomalies of outgoing long-wave radiation for the seasonal average over the Bay of Bengal for the period 1955-2013.

It is clear from table 1 that the mean value of standardized anomalies of geopotential height at $500 \mathrm{hPa}$ of the two periods ADP $(-0.50)$ and IDP (0.59) support the decadal variability.

Tropical cyclones cannot be generated spontaneously. To develop, a pre-existing near-surface disturbance with sufficient vorticity and convergence is required (Gray 1968, 1979). Thus low level relative vorticity at $850 \mathrm{hPa}$ is considered as a potential parameter in the present study. Climatological value of this parameter is well correlated with the global tropical cyclone formation regions (McBride 1995). The time series plots (figure 6) for 11-year running mean of standardized anomaly of vorticity at $850 \mathrm{hPa}$ show a decreasing trend with $95 \%$ confidence level. The decreasing trend vorticity in the lower troposphere in IDP period is unfavourable for tropical cyclone genesis and is connected with the pronounced decrease in cyclone activity over the $\mathrm{BOB}$ region. The mean values of vorticity anomaly (table 1) in IDP (0.02) is also less than the ADP (0.08).

A primary factor in the formation of a tropical cyclone is the warming of a column of air by latent heat released during convection. If this heating occurs sufficiently, it will lower the surface pressure and begin a cyclonic circulation and inflow.
Large values of vertical wind shear prevent this process from occurring since they remove heat from the air column (Gray 1968). Thus tropical cyclones are more likely to form in regions with low vertical wind shear (e.g., McBride and Zehr 1981). The 11year running mean of standardized anomaly of vertical wind shear between 850 and $200 \mathrm{hPa}$ (figure 7) shows a significant increasing trend with $99.9 \%$ significance level, which is just the opposite to that of the decreasing trend of TC frequency during the post-monsoon season. The anomaly is large negative around 1965 and it is almost negative till 1986 and after that the value is positive. The variations are strong opposite in phase with TC frequency in both the periods. The mean value of standardized anomaly of vertical wind shear in two periods ADP $(-0.12)$ and IDP (0.27) are also consistent with the decadal variability (table 1 ). The strong shear of vertical wind for recent decade is unfavourable for cyclone formation. The result is also consistent with the result of previous study (Gray 1979), strong VWS disrupts the organized deep convection (the so-called ventilation effect) which inhibits intensification of the TCs. These results also show the relationship of $\mathrm{TC}$ activity and vertical wind shear over the BOB as discussed by Xavier and Joseph (2000). 


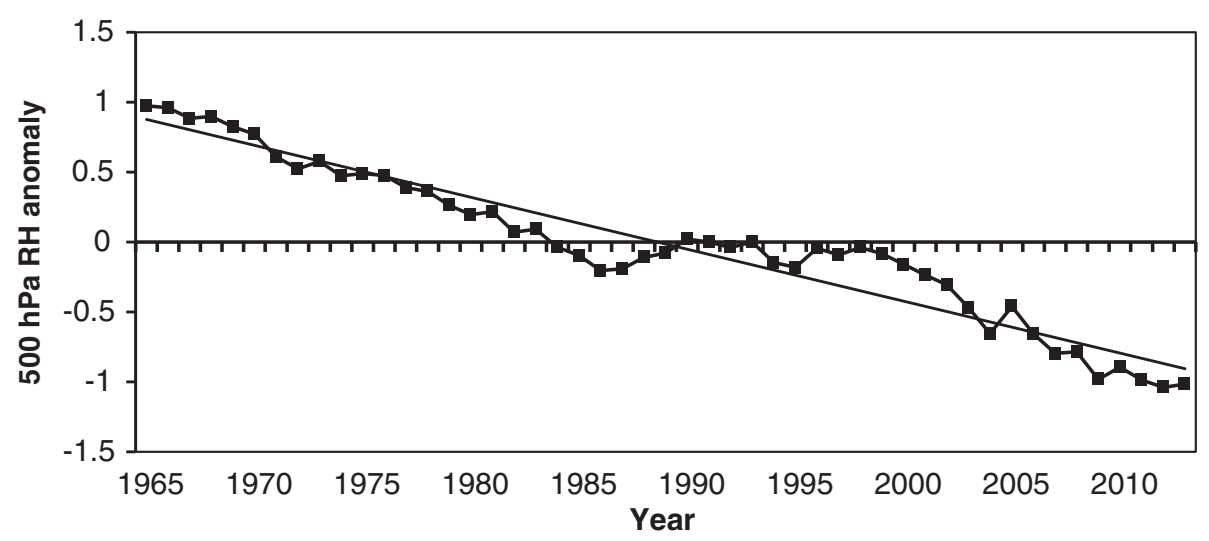

Figure 9. 11-year running mean of standardized anomalies of relative humidity at $500 \mathrm{hPa}$ for the seasonal average over the Bay of Bengal for the period 1955-2013.

The outgoing long wave radiation may be one of the important parameter for TC genesis because the low value of OLR leads to active convection and favourable conditions for TC genesis. Figure 8 shows 11-year running mean of standardized anomalies of OLR. The anomaly is large negative around 1965 and then increases till mid-1980s. It changes sign to positive around 1984. From 1984 till late 1990s, the OLR anomaly is almost positive value and after that there is a small period with negative anomaly and then it maintains its positive value. The OLR also shows the significant $(99.9 \%)$ increasing trend. The positive value of anomaly for IDP is unfavourable for cyclone formation as high OLR value leads to less convection over the sea region. Table 1 shows that the mean value of standardized anomaly of OLR in two periods ADP (0.23) and IDP (0.16) anomaly are in opposite signs.

Gray (1979) and numerous other researchers have found that the middle tropospheric humidity also plays a very crucial role in sustaining the deep convection. Higher the mid-level humidity, the longer a parcel of air can remain saturated as it entrains the surrounding air during its ascent. Vigorous convection occurs if the parcel remains saturated throughout its ascent. The 11-year running mean of standardized anomaly of middle troposphere $(500 \mathrm{hPa})$ humidity are shown in figure 9 . It is seen from figure 9 that the anomaly in the recent decade IDP are almost negative and unfavourable for cyclone genesis and the result is physically significant as dry midlevel suppresses the continuing development of widespread, deep convection over the study area and also consistent with variation of cyclone frequency. The humidity factor shows a decreasing trend and is significant at $99 \%$ level. It is clear from table 1 that the mean value of standardized anomalies of humidity anomaly at $500 \mathrm{hPa}$ of the two periods ADP $(0.39)$ and IDP $(-0.40)$ also support the decadal variability.

\section{Concluding remarks}

The study of long-term variability of tropical cyclone frequency over the Bay of Bengal (BOB) for the post-monsoon season has received relatively less attention as compared to other world ocean basin. Therefore, an attempt has been made to investigate the inter-decadal changes in postmonsoon cyclone frequency over the BOB. A large variability of cyclone formation in annual and postmonsoon season is observed. The frequency of tropical cyclones formed over the Bay of Bengal both in annual and post-monsoon seasons for the period 1955-2013 shows a significant decreasing trend.

In this study, the inter-decadal changes of tropical cyclone frequency in post-monsoon season associated with changes in the $\mathrm{OHC}_{700}$ at $700 \mathrm{~m}$ and the large scale environmental conditions including SST are investigated. The whole analysis period is divided into two periods ADP (1955-88) and IDP (1989-2013), respectively using change point analysis. The 11-year running mean of standardized anomalies of SSTs, $\mathrm{OHC}_{700}$ and the large scale atmospheric parameters such as geopotential height at $500 \mathrm{hPa}$, relative vorticity at 850 $\mathrm{hPa}$, vertical wind shear of zonal wind, outgoing long-wave radiation, relative humidity at 500 $\mathrm{hPa}$ averaged over BOB during the post-monsoon season has been studied comprehensively for the period 1955-2013. The result inferred that the tropical cyclone (TC) activity over the BOB shows a significant inter-decadal variation during 19552013, with two distinct active and inactive periods. The overall TC activity shows a significant decrease in spite of increasing both oceanic parameters $\mathrm{OHC}_{700}$ and SSTs in recent decade (IDP). The variations of other large scale atmospheric parameters show significant relation with the variation of tropical cyclone frequency in both the periods ADP and IDP. Relative to the ADP period (active), warmer $\mathrm{SST}$ and $\mathrm{OHC}_{700}$, weaker low level 
vorticy, high vertical wind shear, high geopotential height at $500 \mathrm{hPa}$, high outgoing long-wave radiation and less mid-tropospheric relative humidity at $500 \mathrm{hPa}$ are observed in IDP period (inactive) in the study area. Thus, the frequency of the tropical cyclone is attributed to the variation in the atmospheric dynamic and thermodynamic conditions rather than the variation of oceanic parameters $\mathrm{OHC}_{700}$ and SSTs during the post-monsoon season.

\section{Acknowledgements}

The authors are grateful to the Director General of Meteorology, India Meteorological Department, New Delhi for providing all the facilities to carry out this research work. The authors acknowledge the use of NCEP and NCAR data in this research work.

\section{References}

Ali M M, Jagadeesh P S V and Jain S 2007 Effects of eddies and dynamic topography on the Bay of Bengal cyclone intensity; EOS Trans. AGU 88 93-95.

Belanger J I, Webster P J, Curry J A and Jelinek M T 2012 Extended prediction of North Indian Ocean tropical cyclones; Wea. Forecasting 27 757-769.

Bindoff N, Willebrand J, Artale V and Cazenave A et al. 2007 Observations: Oceanic climate change and sea level; In: Climate change 200\%: The physical science basis (eds) Solomon S, Qin D, Manning M, Chen Z, Marquis M, Averyt K B, Tignor M and Miller H L, Contribution of working group I to the fourth assessment report of the intergovernmental panel on climate change (Cambridge, UK and New York, USA: Cambridge University Press), pp. 385-431.

Chu P S 2002 Large-scale circulation features associated with decadal variations of tropical cyclone activity over the central North Pacific; J. Climate 15 2678-2689.

Chu P S, Zhao X, Lee C T and Lu M M 2007 Climate prediction of tropical cyclone activity in the vicinity of Taiwan using the multivariate least absolute deviation regression method; Terres. Atmos. Oceanic Sci. 18 805-825, doi: 10.3319/TAO.2007.18.4.805(A).

Elsner J B, Jagger T and Niu X-F 2000 Changes in the rates of North Atlantic major hurricane activity during the 20th century; Geophys. Res. Lett. 27 1743-1746.

Emanuel K A 1999 Thermodynamic control of hurricane intensity; Nature 401 665-669.

Gera A, Mitra A K, Mahapatra D K, Ali I, Rajagopal E N and Basu S 2013 Sea surface height and upper ocean heat content variability in Bay of Bengal during contrasting monsoons 2009 and 2010; Report: http://www.ncmrwf. gov.in/NMRF_RR_OCN1-mar2013SSHA_UOHC.pdf.

Goni G, DeMaria M, Knaff J, Sampson C, Ginis I, Bringas F, Mavume A, Lauer C, Lin I-I, Ali M M, Sandery P, RamosBuarque S, Kang K, Mehra A, Chassignet E and Halliwell G 2009 Applications of satellite-derived ocean measurements to tropical cyclone intensity forecasting; Oceanography 22(3) 190-197, doi: 10.5670/oceanog.2009.78.

Gray W M 1968 Global view of the origin of tropical disturbances and storms; Mon. Wea. Rev. 96 669-700.
Gray W M 1975. Tropical cyclone genesis; Dept. Atmos. Sci., Paper No. 234, Colorado State University, Ft. Collins, CO, 121p.

Gray W M 1977 Tropical cyclone genesis in the western North Pacific; J. Meteorol. Soc. Japan 55 465-482.

Gray W M 1979 Hurricanes: Their formation structure and likely role in the tropical circulation; In: Meteorology over the tropical oceans (ed.) Shaw D B, Royal Meteorological Society, pp. 155-218.

Jayanthi N 1997 An objective analysis of tropical cyclones of the North Indian Ocean with special reference to track prediction capabilities over the Bay of Bengal and Arabian Sea; PhD thesis, University of Madras.

Joseph P V and Xavier Prince K 1999 Monsoon rainfall and frequencies of monsoon depressions and tropical cyclones of recent 100 years and an outlook for the first decades of the 21st century; Proceedings of TROPMET-1999 symposium, 364p.

Kotal S D, Roy Bhowmik S K, Kundu P K and Das A K 2008 A statistical cyclone intensity prediction (SCIP) model for Bay of Bengal; J. Earth Syst. Sci. 117 157-168.

Kotal S D, Kundu P K and Roy Bhowmik S K 2009 Analysis of cyclogenesis parameter for developing and nondeveloping low-pressure systems over the Indian Sea; Nat. Hazards $\mathbf{5 0}$ 389-402.

Leipper D F and Volgenau D 1972 Hurricane heat potential of the Gulf of Mexico; J. Phys. Oceanogr. 2 218-224.

Levitus S, Antonov J and Boyer T 2005 Warming of the world ocean; Geophys. Res. Lett. 32 L02604.

McBride J L 1995 Tropical cyclone formation: Global perspectives on tropical cyclones; WMO/TD No. 693, Rep. TCP-38, World Meteorological Organization, pp. 63-105.

McBride J L and Zehr R M 1981 Observational analysis of tropical cyclone formation. Part II: Comparison of non-developing versus developing systems; J. Atmos. Sci. 38 1132-1151, http://dx.doi.org/10.1175/1520-0469(1981) $038<1132$ :OAOTCF $>2.0 . \mathrm{CO} ; 2$.

Momin I M, Sharma R and Basu S 2011 Satellite derived heat content in the tropical Indian Ocean; Remote Sens. Lett. 2 269-277.

Mandke S K and Bhide U V 2003 A study of decreasing storm frequency over Bay of Bengal; J. Indian Geophys. Union 7 53-58.

Nath S, Kotal S D and Kundu P K 2013 Analysis of a genesis potential parameter during pre-cyclone watch period over the Bay of Bengal; Nat. Hazards 65 2253-2265.

Neumann C J 1993 Global overview: Global guide to tropical cyclone forecasting; WMO/TC No. 560, Report No. TCP31, WMO Geneva 1.1-1.43.

Palmen E N 1948 On the formation and structure of the tropical hurricane; Geophysica 3 26-38.

Rajeevan M, De U S and Prasad R K 2000 Decadal variation of sea surface temperatures, cloudiness and monsoon depressions in the North Indian Ocean; Curr. Sci. 79 283-285.

Revelle R, Broecker W, Craig H, Keeling C D and Smagorinsky J 1965 Appendix Y4, in restoring the quality of our environment report of the environmental pollution panel; pp. 112-133.

Rossby C 1959 Current problems in meteorology in the atmosphere and sea in motion; Rockefeller Inst. Press, New York, pp. 9-50.

Royer J-F, Chauvin F, Tinbal B, Araspin P and Grimal D 1998 A GCM study of the impact of greenhouse gas increase in the frequency of occurrence of tropical cyclones; Clim. Change 38 307-343.

Shay L K and Brewster Jodi K 2010 Oceanic heat content variability in the eastern Pacific Ocean for hurricane intensity forecasting; Mon. Wea. Rev. 138 2110-2131. 
Shay L K, Goni G J and Black P G 2000 Effects of a warm oceanic feature on Hurricane Opal; Mon. Wea. Rev. 128 1366-1383.

Shyamala B and Iyer B G 1996 Statistical study of cyclonic disturbances in Arabian Sea; Proceedings of TROPMET.

Singh O P and Route R K 1999 Frequency of cyclonic disturbances over the North Indian Ocean during ENSO years; Proceedings of TROPMET-1999 Symposium 297.

Srivastava A K, Sinha Ray K and De U S 2000 Trends in the frequency of cyclonic disturbances and their intensification over Indian seas; Mausam 51(2) 113-118.

Swallow J C 1984 Some aspects of the physical oceanography of the Indian Ocean; Institute of Oceanography Sciences (NERC), Survey, UK 31(6-8) 639-650.
Wang B and Chan J C L 2002 How strong Enso events affect tropical storm activity over the western north pacific; J. Climate 15 1643-1658.

Wada A and Chan J C L 2008 Relationship between typhoon activity and upper ocean heat content; Geophys. Res. Lett. 35 L17603.

Wada A and Usui N 2007 Importance of tropical cyclone heat potential for tropical cyclone intensity and intensification in the western North Pacific; J. Oceanogr. 63 427-447.

Xavier P K and Joseph P V 2000 Vertical wind shear in relation to frequency of monsoon depressions and tropical cyclones of Indian seas; Proceedings of National Symposium Tropmet-2000, January 2000, Cochin, India. 